\title{
Architecture and sound: an acoustic analysis of megalithic monuments in prehistoric Britain
}

\author{
Aaron Watson \& DAVID KEATING*
}

Prehistoric monuments in Britain are often dominant features in the landscape, and archaeological theory has tended to consider the visual and spatial influences of their architecture upon peoples' movement and perception. The articulation of sound within these structures has not been widely discussed, despite evidence which suggests that many monuments provided settings for gatherings of people. This possibility was explored at two contrasting sites in Scotland, a recumbent stone circle and a passagegrave, revealing that the elemental acoustic properties inherent in each may have literally orchestrated encounters with the stones.

Key-words: sound, megaliths, prehistoric monuments, Camster Round, experimental archaeology, Easter Aquorthies, Caithness

\section{Introduction}

It seems unlikely that the world was silent in prehistory. Sound was present in all aspects of peoples' lives - from speech to the manufacture of stone tools. Artefacts from across Europe have been interpreted as musical instruments and many of these, like carved bone pipes, may date back to the Palaeolithic (Megaw 1960; 1968). In Britain, similar evidence in later prehistory is rare and problematic (e.g. Megaw 1984), possibly as a result of the poor preservation of organic matter. The definition of musical instruments is itself unsatisfactory, and it is perhaps more appropriate to consider what Lund (1981: 246) defines as 'sound-producing devices'. These include any agency that can emit sound, from the use of raw materials such as wood, bone or stone, to the human body itself. It is possible to produce unexpectedly sophisticated sounds from very simple artefacts, and even unworked raw materials (Purser 1997). Fragmentary evidence could also be misinterpreted. For example, Lund (1981) has suggested that the remains of ceramic drums in Scandinavia may be lost amongst the mass of sherds in the archaeological record. Furthermore, it is also feasible that vessels used for storage, or other purposes, may perform as percussive devices with only simple modifications. Experimental reconstruction has demonstrated that later prehistoric ceramic containers could have been adapted to perform as effective drums (Purser 1997).

Despite the possibility that people had access to 'sound-producing devices', there has been relatively little discussion of the contexts within which sound may have been used. While archaeologists have considered the echoes present in decorated caves or rock-shelters across the world (Dams 1984; Reznikoff \& Dauvois 1988 (see also Scarre 1989); Dayton 1992), there has been relatively little consideration of the acoustic qualities of artificially constructed monuments in Britain. The few studies in print are encouraging. For example, Devereux \& Jahn (1996) suggest that some ancient structures may resonate in response to the human voice, and Lynch (1973) has discussed the 'roof box' at Newgrange in Ireland as means of communicating with the dead.

It is possible that the highly conspicuous nature of many Neolithic and Early Bronze Age monuments has had a substantial bearing upon

\footnotetext{
* Watson, Department of Archaeology, University of Reading, Reading RG6 6AA, England. A.J.Watson@reading.ac.uk Keating, Department of Cybernetics, University of Reading, Reading RG6 6AY, England. D.A.Keating@reading.ac.uk
}

Received July 1998, accepted 18 September 1998, revised February 1999.

ANTIQUTTY 73 (1999): $325-36$ 


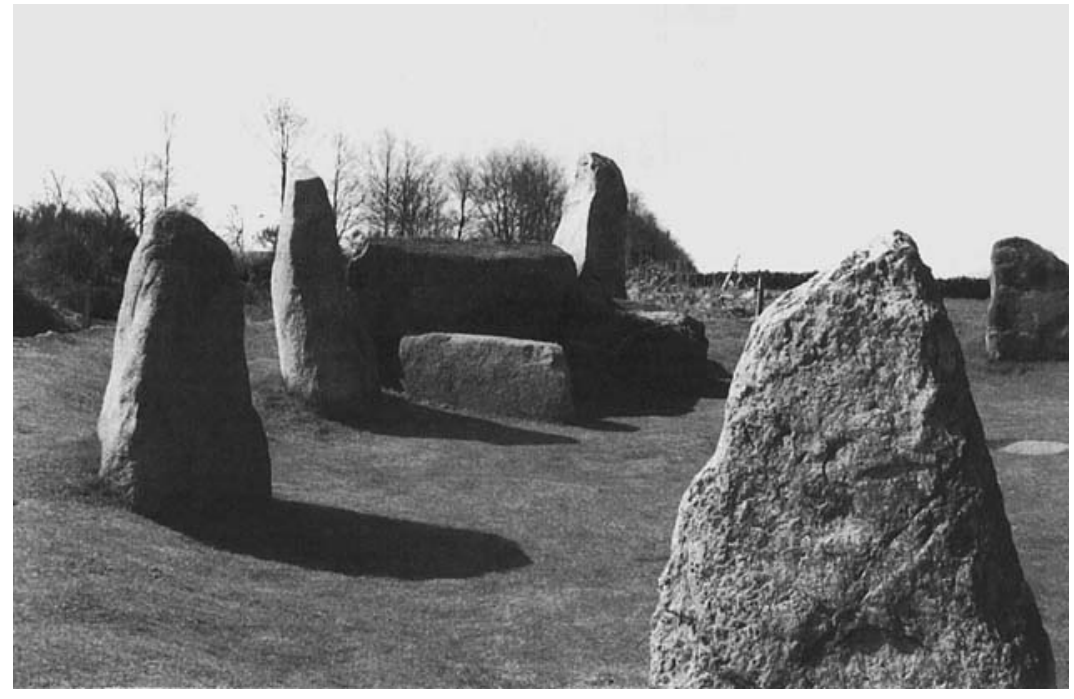

FIGURE 1. The recumbent and its flanking stones at Easter Aquorthies. (Photo Aaron Watson.) their archaeological interpretation. Many of these sites physically dominate their surroundings, and research has tended to emphasize their highly visible characteristics. Consequently, there have been studies of the relationships between architecture and natural topography (e.g. Richards 1996; Bradley 1998), intervisibility and spatial relationships (e.g. Bergh 1995; Woodward \& Woodward 1996), the aesthetics and meaning of construction materials (e.g. Lynch 1998; Parker Pearson \& Ramilisonina 1998) and orientations upon astronomical events (e.g. Ruggles 1984). While these theories add valuable dimensions to our understanding of ancient monuments, they do not consider the possibility that the other senses may have contributed to experiences in the past.

It remained to be seen whether an understanding of acoustics at prehistoric sites could further our understanding of the ways in which prehistoric monuments may have been used. To test this possibility, the acoustic properties of two quite different prehistoric sites in northeast Scotland were explored. The first was Easter Aquorthies, a recumbent stone circle near $\mathrm{Ab}$ erdeen, where a peculiar echo inside the ring appeared to originate from the large recumbent stone. The project then visited the enclosed space of Camster Round, a passage-grave in Caithness, where a wide range of sound effects were recognized. In combination, the results from these studies suggest that the acoustic properties of these sites should be considered alongside visual and spatial analyses.
Acoustic tests at a recumbent stone circle The potential for acoustic phenomena at a stone circle was recognized at Easter Aquorthies, where a curious echo was heard during a visit to the site. Recumbent stone circles possess a number of characteristic features that have primarily been interpreted in visual or aesthetic terms. For example, their standing stones tend to be graded in height towards the southwest, creating a visual focus for the large recumbent block itself, which lies between the two tallest stones. The recumbent at Easter Aquorthies is elaborated by two stones which project from its inner face to form an alcove (FIGURE 1). The stones in the circle also appear to have been chosen for their colour (Lynch 1998). There may have been a cairn inside the monument, but this is likely to be a secondary addition (Shepherd 1987). In addition to these visual and spatial qualities, it appeared that the configuration of Easter Aquorthies could direct sound in rather unexpected ways. The recumbent block and its flanking stones seemed to project speech and other sounds across specific areas of the site, so that they could be heard easily in some areas, but were faint in others. Even with fairly quiet sounds this echo noticeably fluctuated in intensity relative to the position of the listener. In addition, subtler reverberations appeared to originate from different places around the circle, and these could not easily be explained.

Easter Aquorthies was acoustically surveyed on a $2-m$ grid, using an audio amplifier as a sound source. The amplifier was placed in the 


\section{OPEN GROUND}

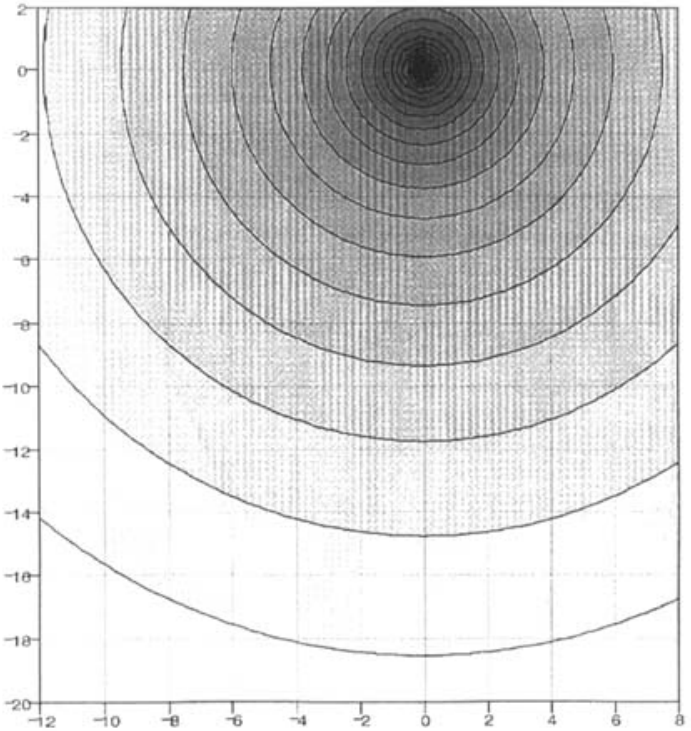

\section{EASTER AQUORTHIES}

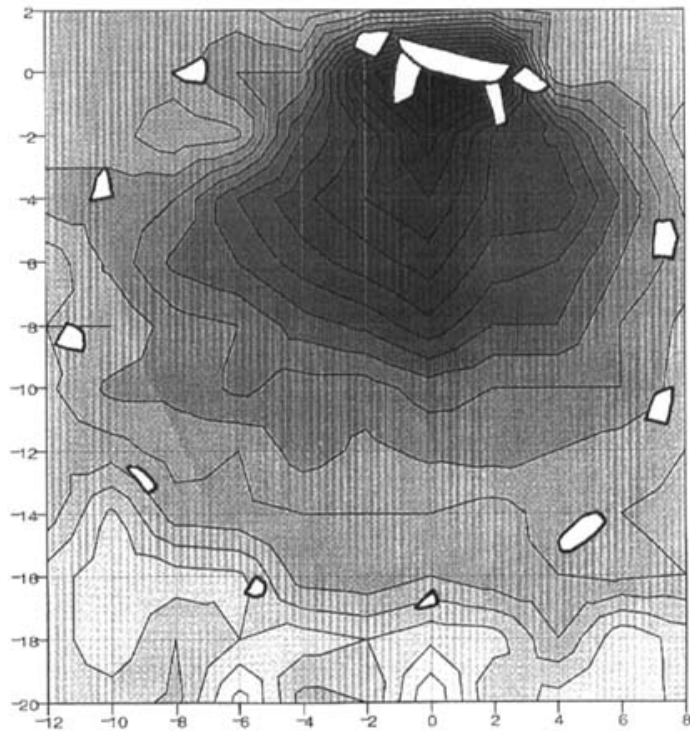

FIGURE 2. The distribution of sound pressure across open ground and from within Easter Aquorthies. The darker greys represent louder volumes and the contours are in increments of 2 decibels. The stones of the circle are shown in outline (from Thom et al. 1980: 162).

alcove created by the recumbent and its surrounding stones, and set to emit a constant pink noise at approximately 100 decibels. Pink noise, which sounds rather like a distant waterfall, was selected as the source sound because it combines a wide range of frequencies that encapsulate the range of sounds that are most likely to have been created in prehistory. Recordings made across the site using an omni-directional microphone and a digital audio tape recorder were converted into decibels using a real-time spectrum analyser. A control experiment using the same equipment was performed in a open environment to provide a comparison.

The results from Easter Aquorthies and the control are shown in FIGURE 2. The contours represent sound pressure in increments of 2 decibels. The control shows a regular decay of sound with distance from the loudspeaker that is entirely in accordance with the physical behaviour of sound. The measurements from Easter Aquorthies itself contrast markedly with the control, demonstrating that the distribution of sound energy is governed considerably by the stones. A spur of higher sound pressure that projects from the recumbent towards the centre of the ring is likely to be the echo heard within the monument. In addition to reflecting sound, the recumbent setting also constitutes an impressive visual backdrop, making this feature comparable to a stage in a theatre. Listeners outside the stone circle would have remained largely unaware of the acoustic effects within. The more complex reverberations perceived by listeners at Easter Aquorthies were too subtle to be captured in this test, although it is suggested that these may result from sound being reflected between individual standing stones in the circle.

\section{Acoustic tests at a megalithic tomb}

The pilot study at Easter Aquorthies confirmed that it was possible to demonstrate the presence of audible phenomena within an open stone circle. As a comparative project, measurements were taken within the enclosed architectural form of a megalithic tomb where it seemed likely that the acoustics would be rather more complex. For the results to be valid it was crucial to examine an intact site, and Camster Round in Caithness was chosen (FIGURE 3). This remote tomb had been restored to its original form in the 1960s using material derived from the site (Davidson \& Henshall 1991). While this 


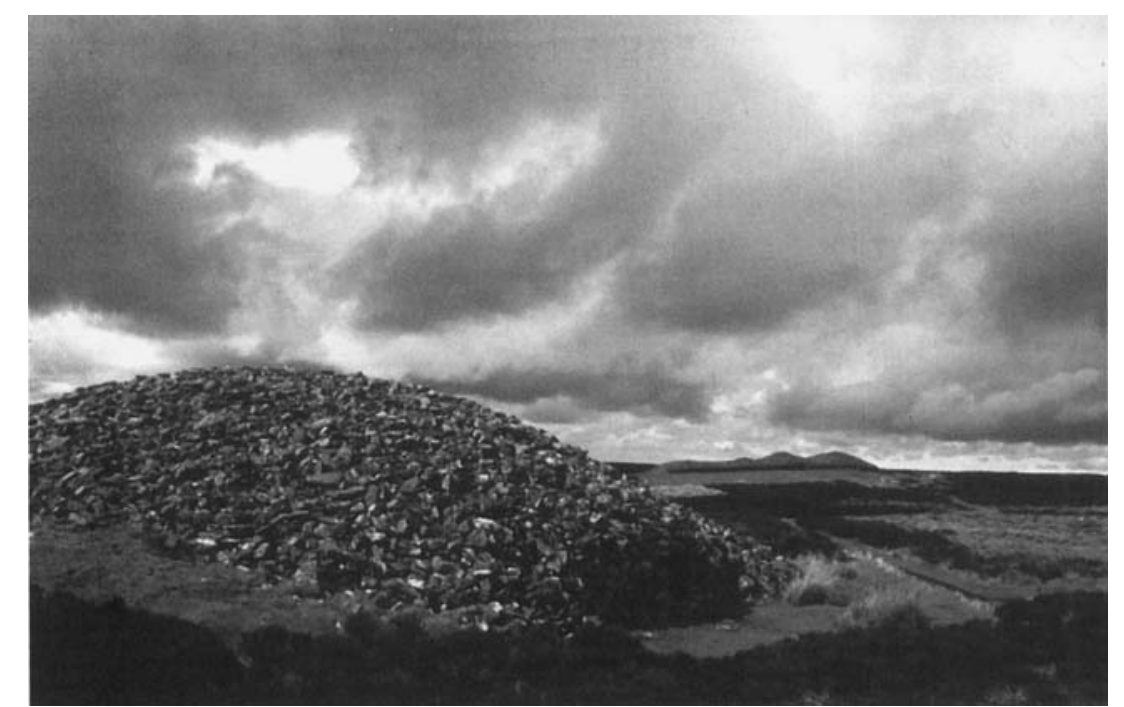

FIGURE 3. View of Camster Round showing the forecourt and entrance. The neighbouring monument of Camster Long can be seen on the horizon. (Photo Aaron Watson.)

renovation cannot have reproduced the tomb's precise prehistoric form, it successfully retained its essential integrity (FIGURE 4). This is not a problem, since minor architectural details would only have a negligible effect on the behaviour of sound. The only modern feature, a glass-plate skylight mounted into the roof of the chamber, was not considered to have any serious impact upon these acoustic tests. In contrast, the nearby monument of Camster Long proved to be quite unsuitable because it had been reconstructed using artificial materials in a manner which varied substantially from the original stone structure.

Camster Round is a passage-grave of the Orkney-Cromarty group (Davidson \& Henshall 1991). This monument consists of a stone-built chamber that is enclosed by a cairn of boulders. A narrow passageway sealed under the cairn enables the chamber to be accessed from the outside world. The cairn is circular in plan, with the chamber placed centrally. On the eastern side of the cairn is a recess, or forecourt, where dry-stone walling enhances the external appearance of the mound to either side of the passage entrance. This façade provides a setting for people to enter or leave the tomb, and has parallels elsewhere in Britain. The first $6 \mathrm{~m}$ of the passageway are rather claustrophobic, being only $0.5 \mathrm{~m}$ wide and about $1 \mathrm{~m}$ high. The passage then broadens into an antechamber, from which the main chamber is accessed through a narrow portal. Within the chamber itself, dry-stone corbelling rises $3 \mathrm{~m}$ above the ground surface and is sealed by a large roof slab.
The cave-like interior was found to have a significant influence upon the behaviour of sound. The evidence for structured deposition within the chambers of passage graves suggests that they were centres of activity, and it seemed reasonable to consider how sound may be disseminated from these innermost spaces. Initially, the interior was surveyed using the same methodology that had been employed at Easter Aquorthies. A loudspeaker was placed with a vertical acoustic axis in the central chamber and set to emit a constant pink noise. Systematic recordings were made using a microphone and digital recorder throughout the monument to assess the horizontal distribution of sound. Three main effects were noted:

1 The stone walls of the chamber reflected rather than absorbed sound waves. This amplified noises and created echoes.

2 Sound was transmitted along the passageway, but gradually softened with distance from the loudspeaker.

3 Outside the tomb, the sound could be heard emerging from the passage entrance, but its amplitude decreased markedly towards the margins of the forecourt. These effects occur because sound waves move more readily through the airspace of the passageway than the enveloping cairn material.

Walking around the outer perimeter of the cairn revealed that sound emerging from the chamber was not constant around the entire circumference. It could be heard easily in some zones, but was indistinct in others. There are 
no external differences in the cairn material that could explain these fluctuations, and they seemed to occur irrespective of noises in the natural environment like wind and rain. It is possible that variations in the density of the cairn material, such as internal walling, could influence the transmission of sound, although it is not known to what extent these features exist within the cairn matrix at Camster Round (Davidson \& Henshall 1991). Alternatively, the fluctuations may result from interference between sound waves simultaneously travelling in both directions away from the passage entrance and recombining at different points around the perimeter.

The filtering effect of the cairn was examined in greater detail by assessing the degree to which different sound frequencies were conveyed from the chamber to the outside world. An amplifier in the chamber was set to broadcast notes which swept from high to low frequencies. By listening to the sound in different places around the monument, it was possible to perceive clear changes. The most complete range of audible frequencies was present in the chamber, along the passage, and immediately outside the entrance. Away from the passage and towards the margins of the forecourt the sound became transformed as the higher notes were lost and bass frequencies became increasingly prominent. Around the sides and back of the monument, the sounds perceived to emerge from the tomb were quite different in nature to those being generated inside the chamber. The elemental movement of sound was altered significantly by the boulders of the cairn, which blocked higherfrequency sounds so that predominantly low frequencies emanated from the monument.

Overall, these tests suggest a disparity between the experiences of people within Camster Round, and those who remained outside. Sounds generated by the occupants of the tomb will be enhanced by echoes, while those listening to these sounds from the outside will only hear a filtered rendition emerge through the cairn. Further experiments revealed that the interior was also suited to a range of peculiar sound effects, such as standing waves.

\section{Standing waves at Camster Round}

Standing waves result from the combination of two waves of equal frequency and intensity travelling in opposite directions, and can be
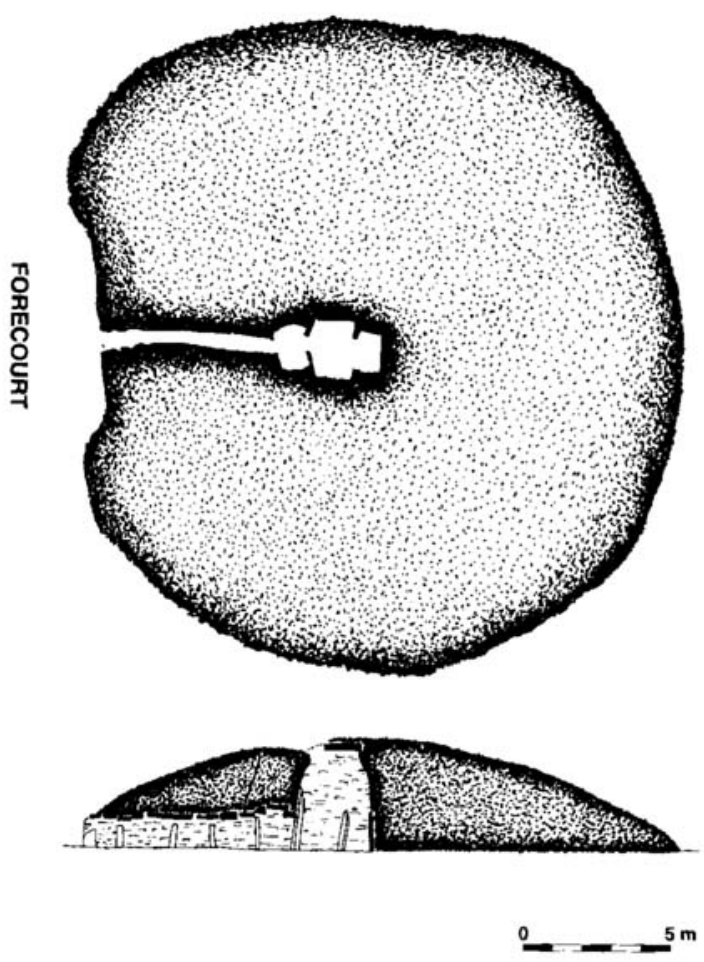

FIGURE 4. A plan and elevation of Camster Round showing the extent of the cairn and details of the chamber and passage (from Davidson \& Henshall 1991: 103).

induced if waves are reflected from a solid surface. Acoustic standing waves result from sound waves being reflected between solid walls, and these produce zones of low or high intensity as waves either cancel or combine (Morse \& Ingard 1986). They can be created in any enclosed space, and were therefore expected to occur in Camster Round under certain conditions. It was not clear, however, which sounds or frequencies would be required to generate them, or what their impact upon listeners would be. Initial mathematical modelling indicated that it should be possible to generate audible standing waves inside the tomb using the human voice or musical instruments. Devereux \& Jahn's (1996) assessment of standing waves at a number of ancient structures (including the passage-graves of Loughcrew and Newgrange in Ireland) also concluded that these could be evoked by vocalization. It remained to assess the physical experience of these wave effects upon participants. 
An electronic tone generator and an amplifier were employed in the manner of Devereux \& Jahn (1996), although it was later demonstrated that a group of people could replicate these effects by vocalization alone. A continuous note was played in the chamber at a variety of pitches until a clearly audible change was heard. A number of frequencies responded in this way, and most were accompanied by a surprising range of effects:

1 The source of the note became unclear. Rather than originating from the loudspeaker, sound appeared to issue from different directions around the chamber. Listeners occasionally perceived these sounds to be contained within their heads, which could be unpleasant.

2 Some standing-wave frequencies created an environment of sound within the monument which could be explored by physically moving around the chamber. Even small movements of the head revealed marked variations in the volume and pitch of the sound.

3 Listeners in the chamber could detect the movement of individuals along the passage, as the solid mass of their bodies created microtonal disturbances in the distribution of sound which could be heard throughout the monument.

4 A timbre that resonated inside the chamber sounded quite ordinary when heard from the exterior. Upon entering the passage, however, it soon became apparent that the sound was behaving in unusual ways. During progress towards the chamber, distinct oscillations in the volume of the note would be perceived in specific places, irrespective of the distance to the loudspeaker. In the antechamber the sound could unexpectedly intensify, change in pitch, and develop vibrato.

5 Speech within the chamber could become seriously distorted, resulting in some extraordinary harmonics.

These effects all resulted from simply playing or vocalizing a continuous note within the chamber, techniques which are unlikely to have been beyond the ability of people in the Neolithic. The possibility remained that percussive instruments in this environment may possess peculiar effects of their own. This constituted the next phase of the project.
The effects of percussion at Camster Round

While it is not possible to generate standing waves with percussive sounds, drums were found to evoke quite different results. The clarity with which percussive sounds moved between the chamber and the outside world varied according to the listeners' location. Like other sounds, drumming was transferred most effectively along the passage, and could be distantly heard in the forecourt. Away from the passage entrance, the sound became increasingly distorted as the high-frequency elements of the drum noise were filtered by the cairn, and the bass was enhanced. Around the sides and back of the tomb, the drumming sounded deep and unfamiliar, and was perceived to be rising up from the ground rather than the tomb itself, which was quite striking.

During these tests it became apparent that drumming could have been used as a form of communication between tombs which were in close proximity. In general, the sound of drumming inside Camster Round did not travel far beyond the cairn, despite the surrounding topography being open. This was due to the dampening effect of the cairn material and interference from natural background sounds like wind. On the day of these tests, drumming in the chamber could not be heard further than $100 \mathrm{~m}$ away from the outer perimeter of the cairn. It was remarkable, therefore, that listeners standing within the chambers of the neighbouring monument of Camster Long, which is approximately $190 \mathrm{~m}$ away (see FIGURE 3 ), did perceive the beat. Although the effect was subtle, the drum could be heard as a distant 'booming' which appeared to rise from the ground. The precise reasons for this remain uncertain, but it is probable that the calm air within Camster Long permitted distant sounds to be perceived more clearly without disturbance from natural sounds in the outside world. It is also possible that the stone shell of both monuments filtered out high-frequency noises while allowing the bass sounds of drumming to be transmitted. These low frequencies are rare in the natural world, and may be disproportionately enhanced relative to other noises in the landscape. This effect could have been exploited elsewhere, where tombs occur in close proximity. An interesting example is Knowth in Ireland, where a large tomb is surrounded by a number of smaller cairns (Eogan 1986). Many of these satellite 
tombs have their passages oriented towards the main mound (FIGURE 5), perhaps assisting the transmission of sound between what were otherwise separate components of a cemetery.

Many of the effects recognized during the previous tests are not unique to passage-graves. They could be recreated at other types of tomb where there is an enclosed chamber. The final series of experiments at Camster Round, however, revealed a remarkable acoustic phenomenon which is entirely reliant upon the specific format of passage-graves.

\section{Passage-graves and Helmholtz Resonance}

Despite variations in size and shape, passagegraves all possess a buried chamber connected to the outside world by a relatively confined passageway. These features encapsulate the critical components of the Helmholtz Resonator, which is recognized for its powerful ability to amplify certain frequencies (Rayleigh 1945; Turner \& Pretlove 1991). To create Helmholtz Resonance, a sound of a specific frequency has to be played in the chamber. This frequency is determined by the relative volumes of the chamber and passage. Sound waves generated in the chamber cause the air to expand, pushing against the mass of air confined within the narrow passageway, and moving it towards the entrance. A critical point is reached when the elastic properties of the air overcome this outward motion, causing the air in the passage to retract back towards the chamber. Helmholtz Resonance occurs when this oscillation becomes synchronized with the pressure waves emitted by the sound source, causing these waves to increase in amplitude. The resulting sound becomes multiplied until it is greater than the original input. An example of Helmholtz Resonance is the sound made by blowing across the neck of a glass bottle.

To test whether passage-graves could resonate when the appropriate sound frequency was played in the chamber, the process was mathematically modelled using the Helmholtz theorem (see below). While the volume of the tomb interior could not be precisely determined due to irregularities in the stonework, it was possible to calculate these dimensions from plans

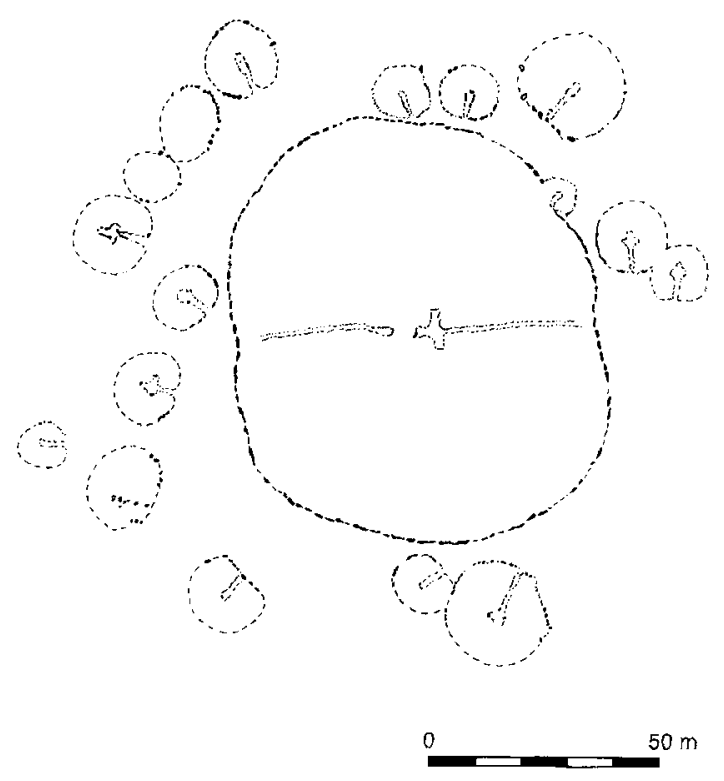

FIGURE 5. A plan of the passage-graves at Knowth, Ireland, showing the distribution of smaller monuments around the central cairn. The approximate outlines of these tombs have been enhanced for clarity (modified from Eogan 1986 23).

within an acceptable margin of error. The results suggested that Camster Round would, in theory, resonate if continuous sounds were generated in the chamber at a frequency of about 4 Hertz. This is an infrasonic frequency, meaning that it is beneath the audible threshold for conventional human hearing. However, infrasonic sound has, in recent years, received considerable attention because of the surprising physical effects it may have on the body and mind. Helmholtz Resonance could, therefore, contribute to the experience of being inside the tomb. It remained to be demonstrated that such a low frequency could be produced.

In the modern world there are no acoustic instruments which can generate a note sufficiently low to induce Helmholtz Resonance at Camster Round. Cathedral organs can achieve some of the lowest notes of any musical instrument at around $16 \operatorname{Hertz}(\mathrm{Hz})$, and it is unlikely that any acoustic instrument in the past or present would be capable of playing a

$$
\text { resonant frequency } \approx \frac{\text { speed of sound }}{2 \pi} \sqrt{\frac{\text { passage cross sectional area }}{\text { passage length } x \text { main body volume }}}
$$




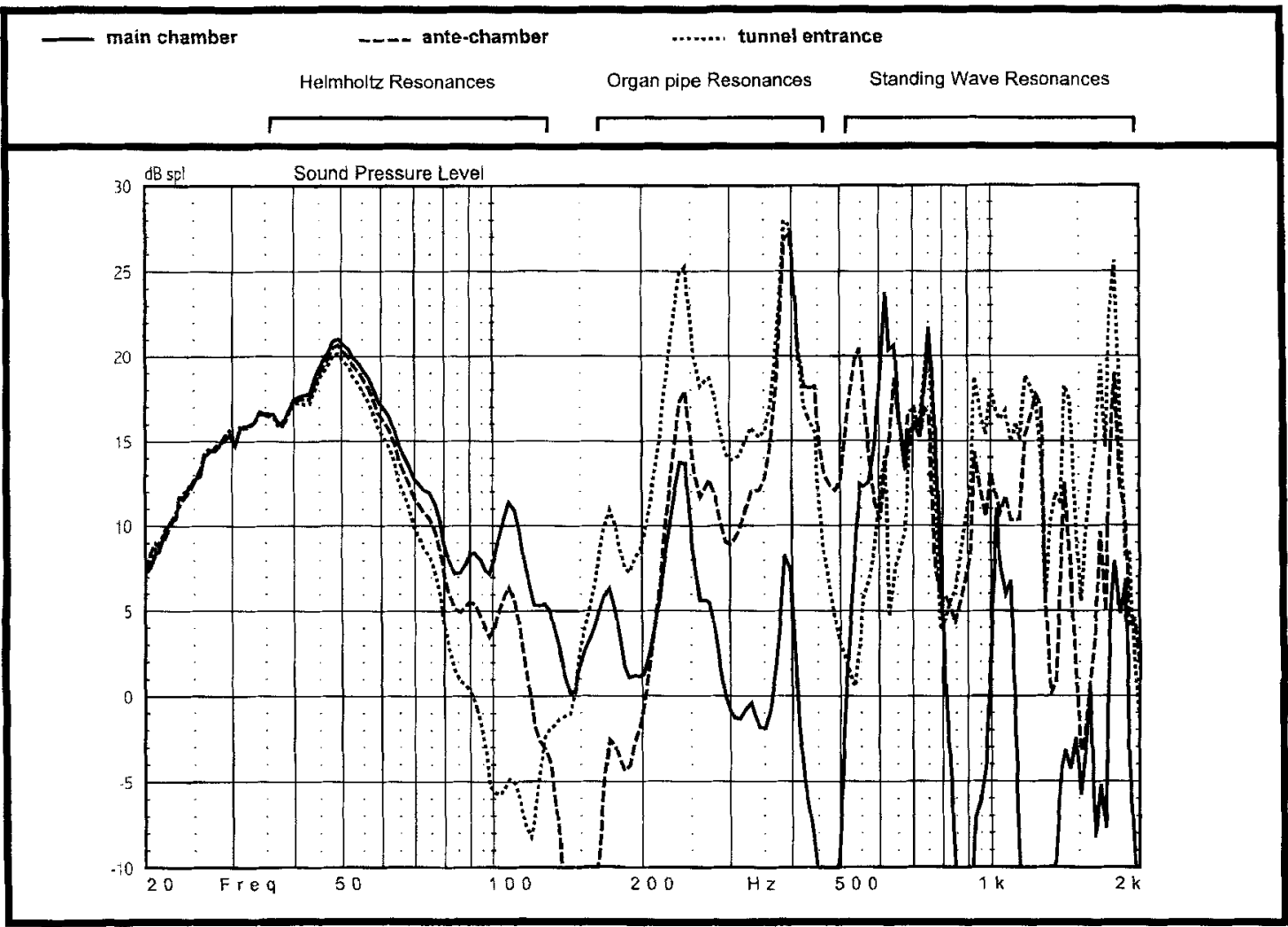

FIGURE 6. Graph showing the frequency responses from different microphone positions within the scale model of Camster Round, illustrating the presence of Helmholtz Resonance, organ-pipe resonance and standing waves.

continuous note at $4 \mathrm{~Hz}$. While it is possible that a strong breeze blowing across the passage entrance with sufficient force may induce Helmholtz Resonance - by stimulating the movement of air within the structure - the conditions under which this would occur are unpredictable and would be infrequent. One remaining possibility was that the infrasonic frequency could be excited artificially by striking a drum at the correct rhythm. At Camster Round this rhythm would have to be a regular beat of 4 beats per second ( $240 \mathrm{bpm})$ in order to generate $4 \mathrm{~Hz}$. It remained to demonstrate that such drumming would produce sufficient energy to excite Helmholtz Resonance, and that the resulting effect could be perceived by people within the tomb.

It was beyond the means of this project to employ specialist equipment to measure infrasonic frequencies at Camster Round. Instead, a 1:10 scale model of the passageway and chamber was constructed from medium-density-fi- breboard, a material sufficiently dense to simulate stone at this scale. While the model could not completely emulate the intricacies of the real tomb, it would adequately simulate it at the frequencies under consideration. Cavities within the dry-stone walling may reduce the amplitude of Helmholtz Resonance to some extent, but would not affect the frequency. The acoustic scale model supplemented mathematical modelling by enabling the theory to be tested in three dimensions under controlled conditions. Given the size of the model, it was necessary to re-scale any acoustic response by a factor of 10. This meant that a resonance of 4 $\mathrm{Hz}$ would scale to $40 \mathrm{~Hz}$, permitting its measurement and analysis using conventional equipment. These sounds could then be reconverted to reveal the behaviour of sound within the monument itself.

A sweep of computer-generated tones from infra- to ultrasonic were played into the scale 
model through a loudspeaker mounted in the chamber floor. A microphone measured the resulting responses, which were assessed by a digital sound analyser. This was repeated three times, with the microphone placed in a different part of the model. The range of frequencies that were attained from these recordings are depicted in FIGURE 6. The most substantial response was an increase in sound pressure centred upon frequencies between approximately 40 and $60 \mathrm{~Hz}$. When reduced by a factor of 10 , these results equate with frequencies between 4 and $6 \mathrm{~Hz}$ at Camster Round, and correspond closely with the theoretical prediction for Helmholtz Resonance. The complex peaks and troughs recorded in the higher-frequency spectrum probably represent standing waves within the model. Two significant peaks at 250 and $400 \mathrm{~Hz}$ may result from organ-pipe resonances created as standing waves are established along the length of the passage. These would give the greatest output at the tunnel entrance. The frequency and sound pressure of the narrow bands at higher frequencies vary considerably in relation to the location of the microphone, suggesting that different standing-wave resonances are established in various parts of the structure. This agrees with the results of the tests which explored standing waves at Camster Round. In contrast, the peak between 40 and $60 \mathrm{~Hz}$ possesses a consistently high amplitude at each microphone location within the scale model, meaning that air throughout the interior of the tomb was being excited to a similar extent. Given that this peak also reflects the frequency predicted by mathematical modelling, it seems reasonable to attribute this distinctive response to Helmholtz Resonance.

These results imply that it would be possible to produce Helmholtz Resonance in the chamber, but would this phenomenon have been noticeable? Research into the impact of infrasonic frequencies upon the human body suggests that their harmful nature has been overrated (Broner 1978), but that people exposed to sufficient levels of infrasonics under laboratory conditions can experience a variety of psychological and physiological responses (Evans 1976). While these symptoms are to some extent subjective, particularly as Nussbaum \& Reinis (1985) have demonstrated that responses to infrasonics may vary between individuals, they provide a valuable reference in assessing the possible influence of a $4-\mathrm{Hz}$ resonance inside Camster Round. To calculate the amplitude of Helmholtz Resonance in the tomb, the decibel output of a $30-\mathrm{cm}$ diameter drum was measured and calibrated against the scale model tomb. This suggested that a single drum was capable of generating approximately 4 to $5 \mathrm{~Hz}$ at between 120 and 130 decibels inside Camster Round. According to Evans (1976: 107), this level of exposure could result in balance disturbance, pressure on the ears, speaking difficulties, vibration, drowsiness and headaches. Any increase in either frequency or sound pressure would intensify the severity of these symptoms.

To assess whether any unusual effects could be detected at Camster Round, drumming tests of short duration were conducted within the tomb in the presence of an audience. While the experiences of these people remain broadly subjective, given that individual responses to sound may vary, many of the listeners did complain of a range of unfamiliar sensations which correlate with those which could be expected from infrasonics (Evans 1976). In particular, participants felt that their pulse and breathing pattern was being influenced, raising the possibility that long-term exposure could result in hyperventilation. While it is possible that the noise and rhythm of drumming in the enclosed environment could itself influence behaviour, there were fewer complaints during equally loud sequences at beats which were too slow to excite Helmholtz Resonance. All of the reported sensations declined rapidly when the drumming ceased. Although the presence of infrasonics in sufficient quantities to influence people could not be absolutely confirmed, it was certainly apparent that the tomb interior was conducive to the creation of unusual experiences.

\section{Resonance and passage-graves across Britain}

Helmholtz Resonance would not be restricted to Camster Round, and the resonant frequencies of a sample of other passage-graves were calculated by deducing their internal volumes from plans and elevations. This was only attempted if their structure was sufficiently well preserved to permit the reconstruction of their original morphology. The frequency of resonance at each site broadly reflects their size, which varies considerably (FIGURE 7): 

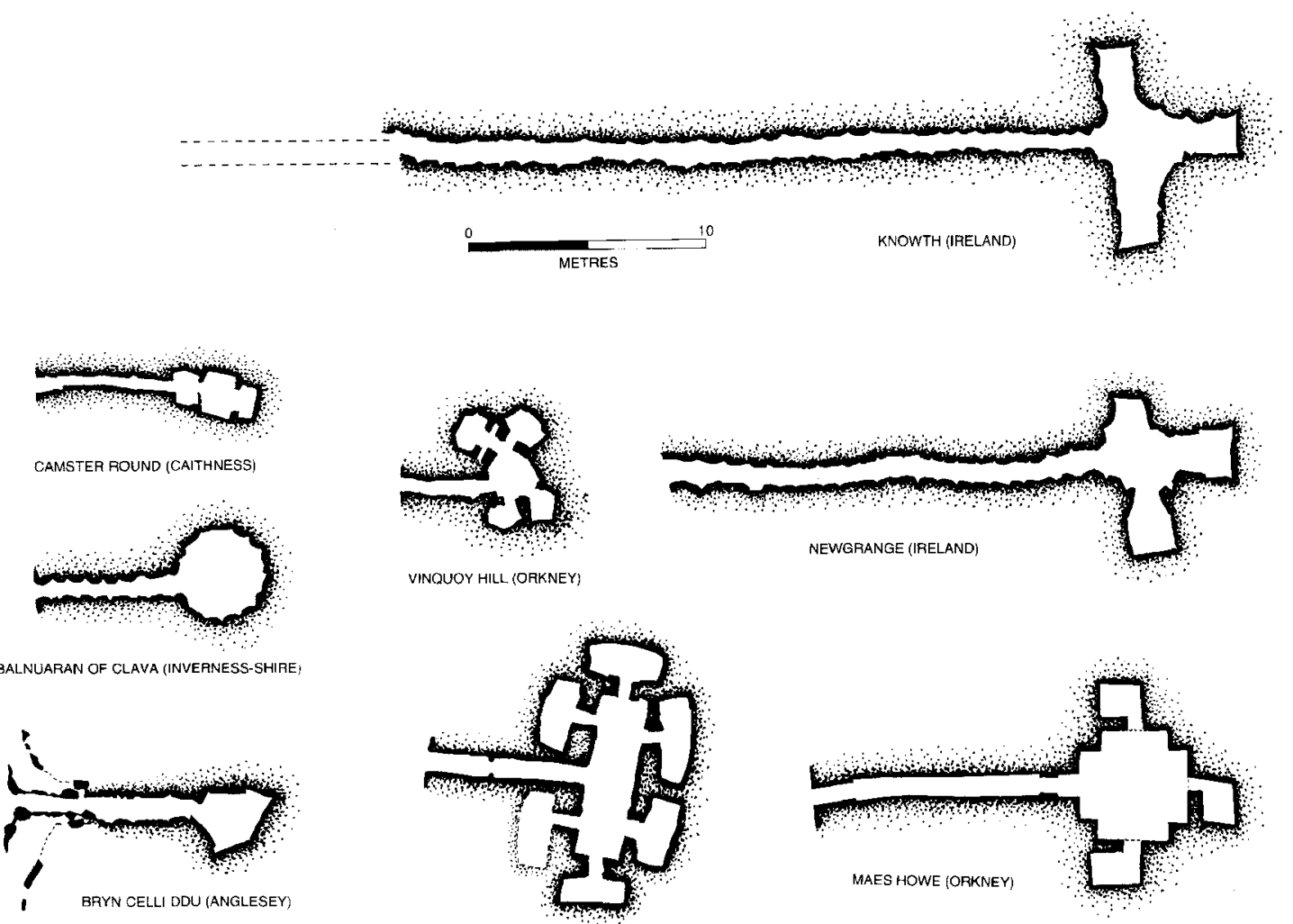

QUANTERNESS (ORKNEY)

FIGURE 7. Plans of passage-grave chambers that are sufficiently complete to allow their resonant frequencies to be calculated.

Bryn Celli Ddu (Wales)

Vinquoy Hill (Scotland)

Camster Round (Scotland)

Balnuaran of Clava Northeast (Scotland)

Maes Howe (Scotland)

Quanterness (Scotland)

Newgrange (Ireland)

Knowth (Ireland)

In general the larger tombs have lower resonant frequencies, and would require a slower drum-beat to evoke Helmholtz Resonance. Groups of tombs with comparable internal volumes will have similar frequencies, irrespective of their precise morphology.

It was not possible, however, to demonstrate empirically the presence of infrasonics within Camster Round, or to test further the effects of drumming upon people. The effects of rhythm or noise can affect people in many different ways, both physical and psychological. Drumbeats are often associated with activities which seek to create links with the supernatural, and are often associated with ritual procedures across the world (Neher 1962; Needham 1967). In part, this may reflect the potential for drums to emit rhythms at loud volumes (Huntington \& Metcalf 1991: 67), but it has also been proposed that the sound waves produced by percussive instruments may contribute to the inducement of altered states of consciousness (Neher 1962; Needham 1967; Jackson 1968). Tuzin (1984) has speculated that an infrasonic component of thunderstorms may contribute to feelings of anxiety, disquiet and, ultimately, altered states of mind.

\section{Discussion}

This project has considered a wide range of acoustic effects that are present at two quite different prehistoric monuments, a recumbent stone circle and a passage-grave. The elemental movement of sound has been considered, as well as the intriguing possibilities of standing waves and Helmholtz Resonance. Yet acous- 
tics should not be restricted to these monuments alone. The physical scale of the earthworks and stone settings at many Neolithic and Early Bronze Age monuments makes them ideal subjects for acoustic effects. The enclosed chambers within tombs may have the most dramatic influence. While this study has focused upon passage-graves, other kinds of chambered tombs, for instance the Cotswold-Severn long barrows, are likely to exert a different influence on the movement of sound. While their configuration is unsuited to Helmholtz Resonance, phenomena like standing waves remain a possibility, as Devereux \& Jahn (1996) have demonstrated at Wayland's Smithy in Berkshire.

As the results from Easter Aquorthies testify, acoustic effects need not be restricted to tombs. An open-air site like a henge, which is surrounded by an earthwork, may also interrupt the passage of sound. Like the earthwork baffles along major roads today, embankments can create considerable sound 'shadows', which may have served to isolate henge interiors from the surrounding landscape. Features like coves, which regularly consist of three large megaliths set at right angles to create an alcove (Burl 1988), have a considerable potential to direct and focus sound. This is difficult to demonstrate, since none of these sites are complete, although the flat stones used in the Cove within Avebury may have a considerable potential to create unusual echoes. Like the recumbent at Easter Aquorthies, these stones would have directed sound in one direction, while filtering it in others. The close-set standing stones at Stonehenge would also have influenced the distribution of sound. When this monument was complete, the dressed surfaces of the sarsen blocks would have created an almost continuous wall around the central area. This may have reverberated sound around the interior, and interrupted or distorted the transmission of sound between the centre and the outside world.

Despite being open to the sky, the fundamental behaviour of these monuments is similar to Camster Round in the sense that people who were outside the monument would not clearly be able to perceive, through either sound or vision, the activities taking place within. At Easter Aquorthies, it was shown that an echo created by the recumbent stone was mainly contained within the interior of the ring of standing stones. The limited internal areas of these structures may have precluded large gatherings of people, and only those permitted within certain parts of these monuments would have experienced unusual acoustics. Such effects may have been a significant contribution to the experience of participation, particularly inside megalithic tombs, where darkness, the presence of the dead and sound effects may have combined to create a memorable experience. In this sense, acoustic effects could serve to differentiate between people who were permitted access and those who were not. Participants inside a tomb would hear sounds enhanced by echoes, while those outside would only perceive filtered sound emerging from the cairn. This may have heightened a sense of mystery regarding the unseen activities within the tomb and empowered those who were able to produce such marked transformations of sound when in the presence of the dead.

The evidence for Neolithic and Early Bronze Age domestic settlements across many regions of Britain suggests that dwellings were ephemeral and may have been built of wood. The size of these dwellings, and the scale of their construction, implies that their acoustic potential was considerably less than stone-built circles and tombs. This may have further differentiated monuments from the everyday, because sound effects within these settings could not have been reproduced at domestic sites in the surrounding landscape.

\section{Conclusion}

Prehistoric monuments may not have been as peaceful during their use as they are today. While these sites can be interpreted as a means by which people in the past structured space to emphasize their social order, studies at a stone circle and a passage-grave suggest that some of these places were also ideal environments for producing dramatic sound effects. While it cannot be demonstrated that the architecture of monuments was deliberately configured to enhance acoustic performance, the behaviour of sound would have been an unavoidable factor in their use. Perhaps acoustics should be regarded as an inseparable component in the genesis of potent events, particularly as many of these compelling sound effects could not have been explained without our modern awareness of physics. In this respect, acoustics should be considered alongside the structural, spatial, or 
visual attributes of ancient monuments. These places may not have been simply a technology for producing visual and acoustic experiences, but a means of creating different worlds altogether.

Acknowledgements. Thanks to Richard Bradley, Nicky Clarkson, Andy Jones and Tim Phillips for their invaluable

\section{References}

BERGH, S. 1995. Landscape of the monuments: a study of the passage tombs in the Cil Irra region, Co. Sligo, Ireland. Stockholm: Riksantikvarieämbetet Arkeologiska Undersökniger, Skrifter nr 6.

BRADLEY, R. 1998. Ruined buildings, ruined stones: enclosures, tombs and natural places in the Neolithic of south-west England, World Archaeology 30: 13-22.

BRONER, N. 1978. The effects of low frequency noise on people a review, Journal of Sound and Vibration 58: 483-500.

BurL, A. 1988. Coves: structural enigmas of the Neolithic, Wiltshire Archaeological and Natural History Magazine 82: 1-18.

Dams, L. 1984. Preliminary findings at the 'Organ' Sanctuary in the cave of Nerja, Malaga, Spain, Oxford Journal of Archaeology 3: 1-14.

DAVIDSON, J.L. \& A.S. HENSHALL. 1991. The chambered cairns of Caithness. Edinburgh: Edinburgh University Press.

DAYTON, L. 1992. Rock art evokes beastly echoes of the past, New Scientist 28 November: 14.

DEvereuX, P. \& R.G. JAHN. 1996. Preliminary investigations and cognitive considerations of the acoustical resonances of selected archaeological sites, Antiquity 70: 665-6.

EOGAN, G. 1986. Knowth and the passage-tombs of Ireland. London: Thames \& Hudson.

Evans, M.J. 1976. Physiological and psychological effects of infrasound at moderate intensities, in W. Tempest (ed.), Infrasound and low frequency vibration: 97-113. London: Academic Press.

Huntington, R. \& P. METCALF. 1991. Celehrations of death: the anthropology of mortuary ritual. New York (NY): Cambridge University Press.

JACKSON, A. 1968. Sound and ritual, Man 3: 293-9.

LunD, C. 1981 . The archaeomusicology of Scandinavia, World Archaeology 12: 246-65.

LYNCH, F. 1973. The use of the passage in certain passage graves as a means of communication rather than access, in G. Daniel \& P. Kjærum (ed.), Megalithic graves and ritual: 147-61. Copenhagen: Jutland Archaeological Society. Publication 11.

1998. Colour in prehistoric architecture, in A. Gibson \& D. Simpson (ed.), Prehistoric ritual and religion: 62-7. Stroud: Sutton Publishing.

MEGaW, J.V.S. 1960. Penny whistles and prehistory, Antiquity 34: 6-13.

1968. Problems and non-problems in palaeo-organology: a musical miscellany, in J.M. Coles \& D.D.A. Simpson (ed.), help with the fieldwork, and to Christopher Chippindale, Paul Devereux, Graeme Lawson and Howard Williams for their comments and support. John Perser kindly contributed sound recordings of ancient musical instruments. Thanks also to Brian Hayter of the Music Education Group at Bulmershe Court, Reading University, and to Andrew Colyer, for the loan of percussion instruments. We are grateful to Liam Bassett of the Department of Psychology, Reading University, for constructing the scale model of Camster Round.

Studies in ancient Europe: 333-58. Leicester: Leicester University Press.

1984. The bone ?flute, in W.J. Britnell \& H.N. Savory (ed.), Gwernvale and Penywyrlod: two Neolithic long cairns in the Black Mountains of Brecknock: 27-8. Bangor: Cambrian Archaeological Association. Cambrian Archaeological Monograph 2.

MORSE, P.M. \& K.U. INGARD. 1980. Theoretical acoustics. Princeton (NI): Princeton University Press.

NeEdham, R. 1967. Percussion and transition, Man 2: 606-14.

NEHER, A. 1962. A physiological explanation of unusual behaviour in ceremonies involving drums, Human Biology 34: 151-60.

NuSSBAuM, D.S. \& S. REINIS. 1985. Some individual differences in human response to infrasound. Toronto: University of Toronto Institute for Aerospace Studies. Report 282.

PARKer PeARSON, M. \& Ramilisonina. 1998. Stonehenge for the ancestors: the stones pass on the message, Antiquity 72: $308-26$.

PURSER, J. 1997. The Kilmartin sessions: the sounds of ancient Scotland. Compact disc produced by the Kilmartin House Trust, Argyll: KHT CD1.

RAYLEIGH, J.W.S. 1945. The theory of sound. New York (NY): Dover Publications.

REzNIKOFF, I. \& M. DAUVOIS, 1988. La dimension sonore des grottes ornées, Bulletin de la Société Préhistorique Française 85: 238-46.

RICHARDS, C. 1996. Monuments as landscape: creating the centre of the world in late Neolithic Orkney, World Archaeology $28: 190-208$.

RUGGLES, C.L.N. 1984. Megalithic astronomy: a new archaeological and statistical study of 300 western Scottish sites. Oxford: British Archaeological Reports. British series 123

SCARRE, C. 1989. Painting by resonance, Nature 338: 382.

ShePHERD, I. 1987. The early peoples, in D. Omand (ed.), The Grampian people: 119-30. Golspie: The Northern Times.

THом, A., A.S. THOм \& A. BurL. 1980. Megalithic rings: plans and data for 229 monuments in Britain. Oxford: British Archaeological Reports. British series 81.

TurNer, J.D. \& A.J. PRETLOVE. 1991. Acoustics for engineers. Basingstoke: Macmillan.

TuzIN, D. 1984. Miraculous voices: the auditory experience of numinous objects, Current Anthropology 25: 579-96.

WOODWARD, A.B. \& P.J. WOODWARD. 1996. The topography of some barrow cemeteries in Bronze Age Wessex, Proceedings of the Prehistoric Society 62: 275-91. 